\title{
Simulation Tool for Livestock Feeding: SIMFEED
}

\author{
Neha Khanna ${ }^{a^{*}, \text { Pratiksha Saxena }}{ }^{b}$ \\ Department of Applied Mathematics \\ Gautam Buddha University, Greater Noida, Pin Code- 201308, India \\ E-mails- ${ }^{a}$ neha15khanna@gmail.com, ${ }^{b}$ mathematics.pratiksha@gmail.com \\ *Corresponding author
}

(Received September 7, 2018; Accepted December 27, 2018)

\begin{abstract}
The aim of this paper is to propose a simulation tool: SIMFEED which can formulate balanced livestock feed mix as well as can fulfill the other objectives of the livestock industry such as nutrient variability inclusion, simultaneous achievement of multiple objectives, simulated feed mix etc. Besides the standard problem of formulating balanced livestock feed mix at minimum cost, SIMFEED can also compute feed mix to fulfill different objectives of the user. In SIMFEED, different mathematical models, algorithms and techniques were embedded to formulate balanced livestock feed mix with the consideration of various other needs of the user. SIMFEED can formulate feed mix for different weight classes of livestock. It works on the data stored in the data base as well as on the real world data. The graphical interface is also developed to compare the values of objective function achieved using different techniques. Genetic algorithm is implemented for obtaining more practical feed mix. The artificial neural network is implemented for fine tuning of the feed ingredients present in the feed mix. A simulation technique is also developed for the formulation and computation of the model on the basis of real world data.
\end{abstract}

Keywords- Livestock industry, Balanced feed mix, Cost minimization, Shelf-life maximization.

\section{Introduction}

Animal feed mix is defined as a combination of different feed ingredients used for animal feeding. The feed mix, formulated to provide the appropriate amount of all nutrients required for maintenance and a given level of performance to a specific animal species and class, is termed as a balanced feed mix. Balanced feed mix provides better yields, productivity and nutrient utilization. Animal Feed mix formulation is the process of combining different available feed ingredients into a balanced feed mix which animal can consume, digest and utilize to meet the nutrient needs at different stages.

The general objective of the classical approach of livestock feeding is the formulation of least cost feed mix but in various real life situations, there are many other objectives raised by livestock managers. For example: formulation of feed mix with the inclusion of nutrient variability at the desired probability level, simultaneous achievement of multiple objectives, maximum or minimum inclusion of the desired feed ingredients, maximization of weight gain, maximization of animal yield, simulated feed mix etc. Formulation of livestock feed mix with the consideration of different needs of the livestock industry through a single platform motivates this study. To achieve the various objectives of the livestock industry, different mathematical models have been developed and implemented for livestock feed mix formulation using SIMFEED.

Different issues involved in the formulation of balanced feed mix of livestock leads to the development of various computer programs, tools and software. The basics of ration formulation were described by the computerized linear program (Black and Hlubik, 1980). A method was 
International Journal of Mathematical, Engineering and Management Sciences

Vol. 4, No. 2, 337-348, 2019

https://dx.doi.org/10.33889/IJMEMS.2019.4.2-027

evaluated for selecting dairy ration formulation software for microcomputers (Weaver et al., 1988). A benchmark problem, consisting of 15 activities required in designing dairy rations, was chosen to evaluate ease of use, ease of learning and software performance. The software is developed for mainframe computers, which served as a basis for Computer-Assisted Menu Planning (CAMP) (Lancaster, 1992). A program is developed in Excel Workbook (Roush et al., 2007). This program consisted of two worksheets illustrating linear and stochastic program approaches. A published linear program problem served as a benchmark in the development of the linear and stochastic programs. A user-friendly tool is constructed for beef farmers in an Excel framework (Zgajnar and Kavcic, 2008). In this tool, linear program and weighted goal program were used for beef ration formulation. This tool was applicable for nutritionally balanced and cost-effective beef production. A spreadsheet tool is developed for the formulation of daily cow ration (Zgajnar et al., 2009). The tool was tested for dairy cows with a $25 \mathrm{~kg}$ daily milk yield. A spreadsheet feed problem was set up using 11 ingredients and 11 constraints (Roush et al., 2009). The linear programming and stochastic programming solutions were determined using the Excel Solver Algorithm. An Excel Workbook (Microsoft Corporation, Redmond, WA, USA) is developed using the Excel Solver (Frontline Systems Inc., Incline Village, NV, USA) to optimize energy density and bird performance (Afrouziyeh et al., 2011). A multiple criteria approach is represented to deal with the risk of the farmer's decisions (Zgajnar and Kavčič, 2011). Decisionmaking process was organized in a framework of spreadsheet tool using deterministic and stochastic mathematical programming techniques. An Artificial Neural Networks (ANNs) based soft computing model is applied for empirical interpolation of precipitation in Himalayan region. Feed Forward Back Propagation (FFBP) algorithm is used to develop a Multilayer Perceptron ANN model for empirical downscaling of precipitation in Himalayan region (Joshi, 2016). The stochastic approach with continuous state space is used to design a Software Reliability Growth Model (SRGM) (Singh et al., 2017). Genetic algorithm approach is used to solve reliability redundancy allocation problem of complicated system in fuzzy environment (Sahoo, 2017). A mathematical model is formulated for water pollutants which are soluble and insoluble and numerical simulation is carried out which shows that soluble water pollutants are increasing as compared to insoluble water pollutants (Shah et al., 2018). A portfolio selection model with several objective functions is investigated and a preferable efficient portfolio of the model is obtained (Jana et al., 2018).

Bestmix, Feed formulation, Eco-Mix are some of the software which can evaluate least cost feed mix. This software uses linear programming to find the least cost feed mix. Winfeed is the only software which can provide least cost feed mix using linear as well as stochastic programming techniques.

The above literature review showed that various spread sheets, computer programs and software are developed to achieve the livestock feed mix for fulfilling different needs of the user but these tools are providing feed mix for particular livestock with a specific weight class and physical state. Moreover, most of the programs and software, developed for the formulation of livestock feed mix are based on linear programming technique which provides least cost feed mix formulation. Some of the programs are formulating livestock feed mix on the basis of a combination of two or more mathematical programming techniques.

There is no single interface which can consider all the above stated issues and formulate balanced livestock feed mix. Also, no interface facilitates simulation program which can formulate the model and provide the best possible solution on the basis of real world data. SIMFEED is a 
International Journal of Mathematical, Engineering and Management Sciences

Vol. 4, No. 2, 337-348, 2019

https://dx.doi.org/10.33889/IJMEMS.2019.4.2-027

MATLAB based tool which can consider all the above stated issues on a single platform and formulate livestock feed mix. It can handle multiple objectives and provides balanced livestock feed mix. Simulated feed mix can also be evaluated using SIMFEED. In this paper the objectives, features and execution of SIMFEED are explained.

\section{Material and Methods}

The livestock industry is continuously facing the problem of the inadequate nutritive value of the commercial feed mix, higher feed prices and inconsistent quality of feed mix. SIMFEED is developed to fulfill various needs and objectives of the livestock industry and to formulate the livestock feed mix. It is an effort to provide a single interface to consider various objectives of the user and evaluate the feed mix. This section describes the objectives, models and design of SIMFEED.

\subsection{Objectives of SIMFEED}

Numerous objectives for various weight classes of different livestock can be achieved using SIMFEED. The list of objectives of SIMFEED, fulfilling various needs of the livestock industry, is as follows:

- Least cost feed mix formulation with the satisfaction of the minimum nutrient requirement of various livestock.

- Maximization of shelf-life of feed mix satisfying minimum nutrient requirement of various livestock.

- Least cost feed mix formulation with nutrient variability inclusion at desired probability level.

- Maximization of shelf-life of feed mix with nutrient variability inclusion at desired probability level.

- Simultaneous achievement of three goals: cost minimization, shelf-life maximization and minimum nutrient requirement, for a different hierarchy of priority levels.

- Least cost feed mix formulation for maximum or minimum inclusion of desired feed ingredients.

- Feed mix formulation with maximum shelf-life for maximum or minimum inclusion of desired feed ingredients.

- Least cost feed mix formulation for maximum or minimum inclusion of desired feed ingredients with the inclusion of nutrient variability at a desired probability level.

- Feed mix formulation with maximum shelf-life for maximum or minimum inclusion of desired feed ingredients as well as for the inclusion of nutrient variability at desired probability level.

- Simultaneous achievement of the goals of cost minimization, shelf-life maximization and minimum nutrient requirement with the maximum or minimum inclusion of desired feed ingredients, for a different hierarchy of priority levels.

- Feed mix formulation to control over and under achievement of nutrients.

- Feed mix formulation for cost minimization using genetic algorithm.

- Feed mix formulation for shelf-life maximization using genetic algorithm.

- Simultaneous achievement of cost minimization and shelf-life maximization using genetic algorithm.

- Feed mix formulation for cost minimization with the inclusion of nutrient variability using genetic algorithm. 
International Journal of Mathematical, Engineering and Management Sciences

Vol. 4, No. 2, 337-348, 2019

https://dx.doi.org/10.33889/IJMEMS.2019.4.2-027

- Feed mix formulation for shelf-life maximization with the inclusion of nutrient variability using genetic algorithm.

- Simultaneous achievement of cost minimization and shelf-life maximization with the inclusion of nutrient variability using genetic algorithm.

- Simulation for cost minimization using three-layer artificial neural network to achieve simulated feed mix.

- Simulation for shelf-life maximization using three-layer artificial neural network to achieve simulated feed mix.

- Simulation for simultaneous achievement of cost minimization and shelf-life maximization using three-layer artificial neural network.

- Feed mix formulation with the flexibility of user defined data.

- Formulation of user defined objective function (weight gain maximization, animal yield maximization etc.) on the basis of real world data using simulation technique. This technique provides the combination of nutrients for best value of the objective function.

\subsection{Models for SIMFEED Development}

To achieve the above objectives, total 11 mathematical models and corresponding algorithms and flowcharts are developed and are embedded in SIMFEED for formulating balanced livestock feed mix (Saxena and Khanna, 2017a, 2017b). In developing these models, algorithms and corresponding flowcharts, the objective functions are taken as cost minimization and shelf life maximization. Constraints are formulated on the basis of nutritional requirements of livestock. Linear, Stochastic and Multi-objective programming are implemented in SIMFEED to formulate livestock feed mix. ANN and Genetic Algorithm technique are also used to achieve livestock feed mix. SIMFEED also provides comparison of results using graphical interface. A simulation technique is also developed which is a special and unique feature of this tool. This technique can formulate the objective function on the basis of real world data and provides the best combination of nutrients along with the value of objective function. Some of the models are as follows.

Model to optimize the objective function:

$$
\begin{aligned}
& \min z=\sum_{j=1}^{n} c_{j} x_{j} \\
& \text { s.t. } \sum_{j=1}^{n} a_{i j} x_{j} \geq b_{i} \\
& x_{j} \geq 0, b_{i} \geq 0 \\
& \text { where } i=1 \text { to } m, j=1 \text { to } n
\end{aligned}
$$

where $z$ is the objective function, $c_{j}$ is per unit cost of the $j^{\text {th }}$ feed ingredient, $x_{j}$ is quantity of $j^{\text {th }}$ feed ingredient in the feed mix, $a_{i j}$ is amount of $i^{\text {th }}$ nutrient available in the $j^{\text {th }}$ feed ingredient, $b_{i}$ is minimum requirement of $i^{\text {th }}$ nutrient, $m$ is number of nutrient constraints, $n$ is number of feed ingredients, $i$ is index identifying nutrient components with $i=1,2, \ldots . m, j$ is index identifying feed ingredients with $j=1,2, \ldots \ldots \ldots$. 
International Journal of Mathematical, Engineering and Management Sciences

Vol. 4, No. 2, 337-348, 2019

https://dx.doi.org/10.33889/IJMEMS.2019.4.2-027

Model for nutrient variability inclusion

$$
\begin{aligned}
& \min z=\sum_{j=1}^{n} c_{j} x_{j} \\
& \text { s.t. } \sum_{j=1}^{n}\left(a_{i j}-Z \sqrt{\sum_{j=1}^{n} \sigma_{i j}{ }^{2}}\right) x_{j} \geq b_{i} \\
& x_{j} \geq 0, b_{i} \geq 0 \\
& \text { where } i=1 \text { to } m, j=1 \text { to } n
\end{aligned}
$$

where $\sigma_{i j}{ }^{2}$ represents the variance of $i^{\text {th }}$ nutrient in $j^{\text {th }}$ ingredient and it is included with a certain probability level. The value of $Z$ is taken from the standard normal distribution table corresponding to the desired probability level. Rest of the variables are defined as above.

Model for simultaneous achievement of multiple objectives:

$$
\begin{aligned}
& \min z=\sum_{k=1}^{p} d_{k}^{+}+\sum_{l=1}^{p} d_{l}{ }^{-} \\
& \text {s.t. } \sum_{j=1}^{n} c_{k j} x_{j}+d_{k^{-}}-d_{k}^{+}=z_{k} \\
& \sum_{j=1}^{n} a_{i j} x_{j}+d_{l}{ }^{-}-d_{l}^{+}=b_{i} \\
& x_{j} \geq 0, b_{i} \geq 0 \text { where } i=1 \text { to } m, j=1 \text { to } n
\end{aligned}
$$

where $z$ is the sum of unwanted deviation variables. $p$ is the number of goals. $d_{k}^{+}$is the deviation variable for over achievement of the $k^{\text {th }}$ goal corresponding to cost and shelf-life, $k=1,2, d_{k}{ }^{-}$is the deviation variable for under achievement of the $k^{\text {th }}$ goal corresponding to cost and shelf-life, $k=1,2, d_{l}{ }^{+}$is the deviation variable for over achievement of the $l^{\text {th }}$ goal corresponding to the nutrient requirement, $l=1$ to $m, d_{l}{ }^{-}$is the deviation variable for under achievement of the $l^{\text {th }}$ goal corresponding to the nutrient requirement, $l=1$ to $m$.

\subsection{Design of SIMFEED}

This section provides a brief description of the working of SIMFEED.

The first page of the simulation tool represents the name of the tool - SIMFEED. Start Button is provided just below the name of the tool. To initialize the formulation of livestock feed mix, the Start Button is to be selected by the user. This step is shown in Figure 1. 
International Journal of Mathematical, Engineering and Management Sciences

Vol. 4, No. 2, 337-348, 2019

https://dx.doi.org/10.33889/IJMEMS.2019.4.2-027

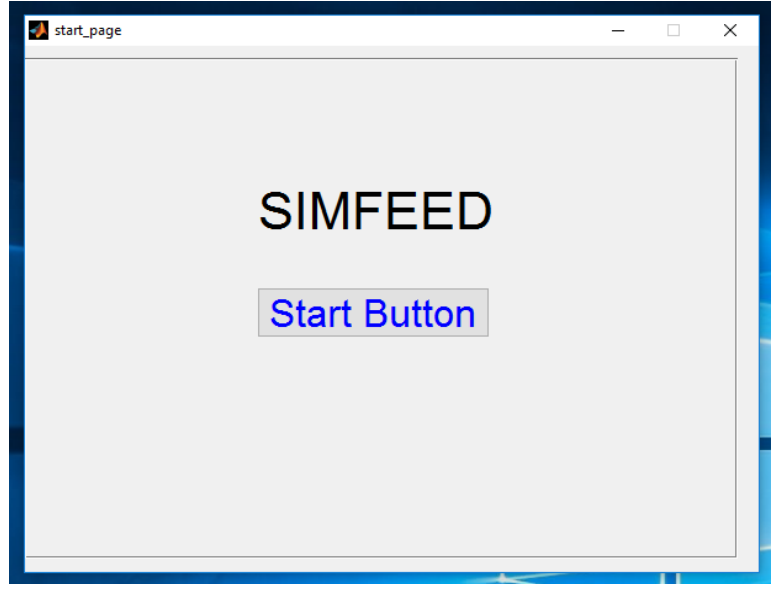

Figure 1. Initialization of the simulation tool

After selecting the Start Button, the next step is to select the animal type and weight class for whom balanced feed mix is to be formulated (Figure 2). After selecting the animal, its class and weight, the next step is to select the desired feed ingredients for the selected animal. It can be done by selecting the Feed Ingredients button on the same screen (Figure 2).

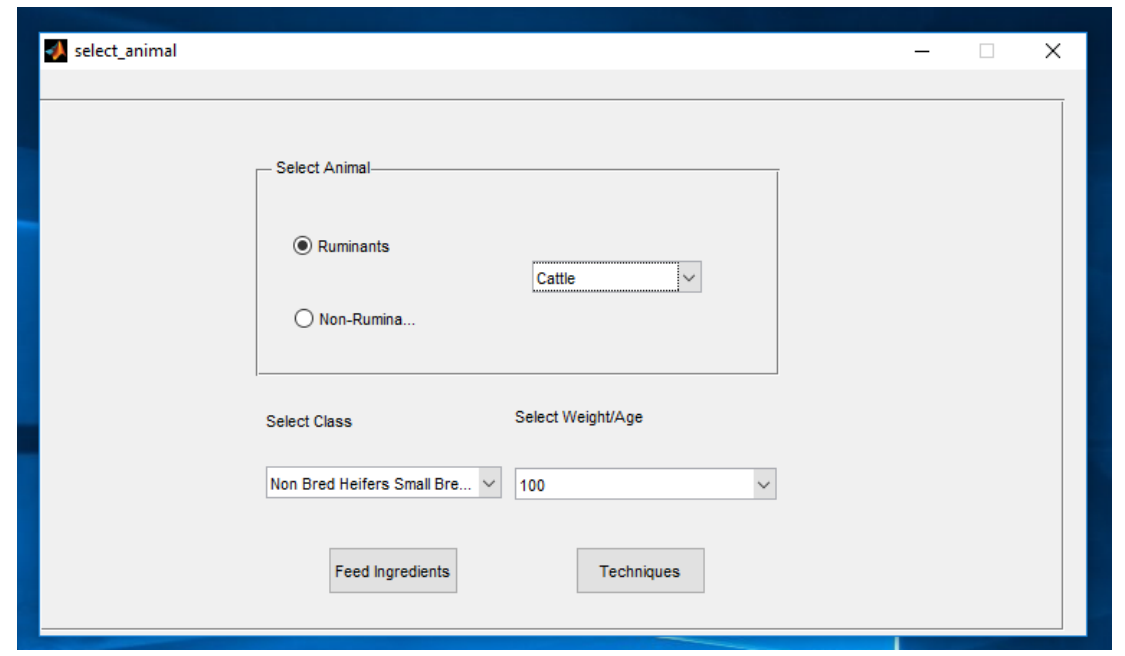

Figure 2. Animal selection screen

On selecting the Feed Ingredients button, it will take the user to the feed ingredients screen. Using this screen, the desired feed ingredients can be selected from the data base or can be entered manually (Figure 3). 
International Journal of Mathematical, Engineering and Management Sciences

Vol. 4, No. 2, 337-348, 2019

https://dx.doi.org/10.33889/IJMEMS.2019.4.2-027

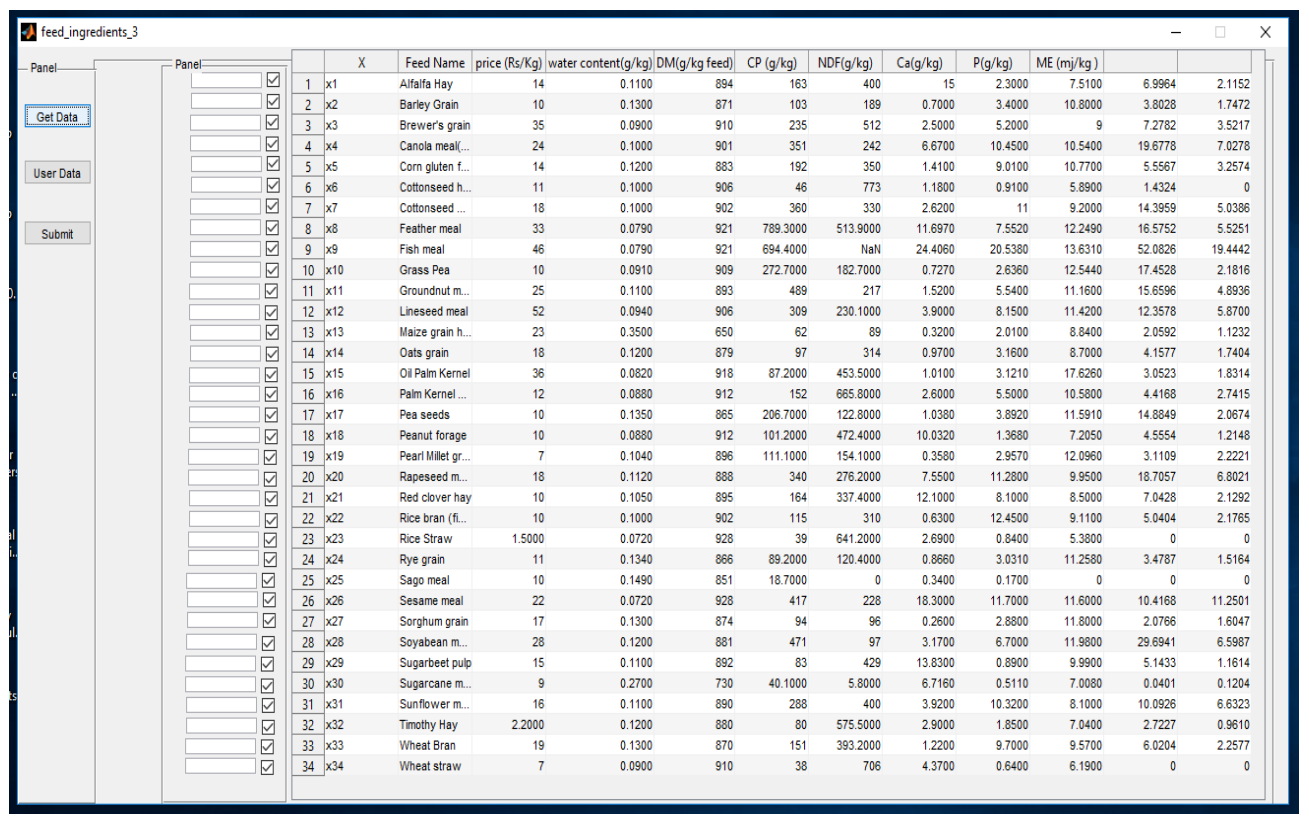

Figure 3. Feed ingredients screen

After submitting the desired feed ingredients, SIMFEED will take the user to the next screen where techniques for mathematical model formulation are described. Now user can select any of the technique (shown in Table 1) and objective from the drop-down list of various objectives and click the Submit button to see the feed mix (Figure 4). After selecting the desired technique, feed mix will be evaluated and shown on the output screen.

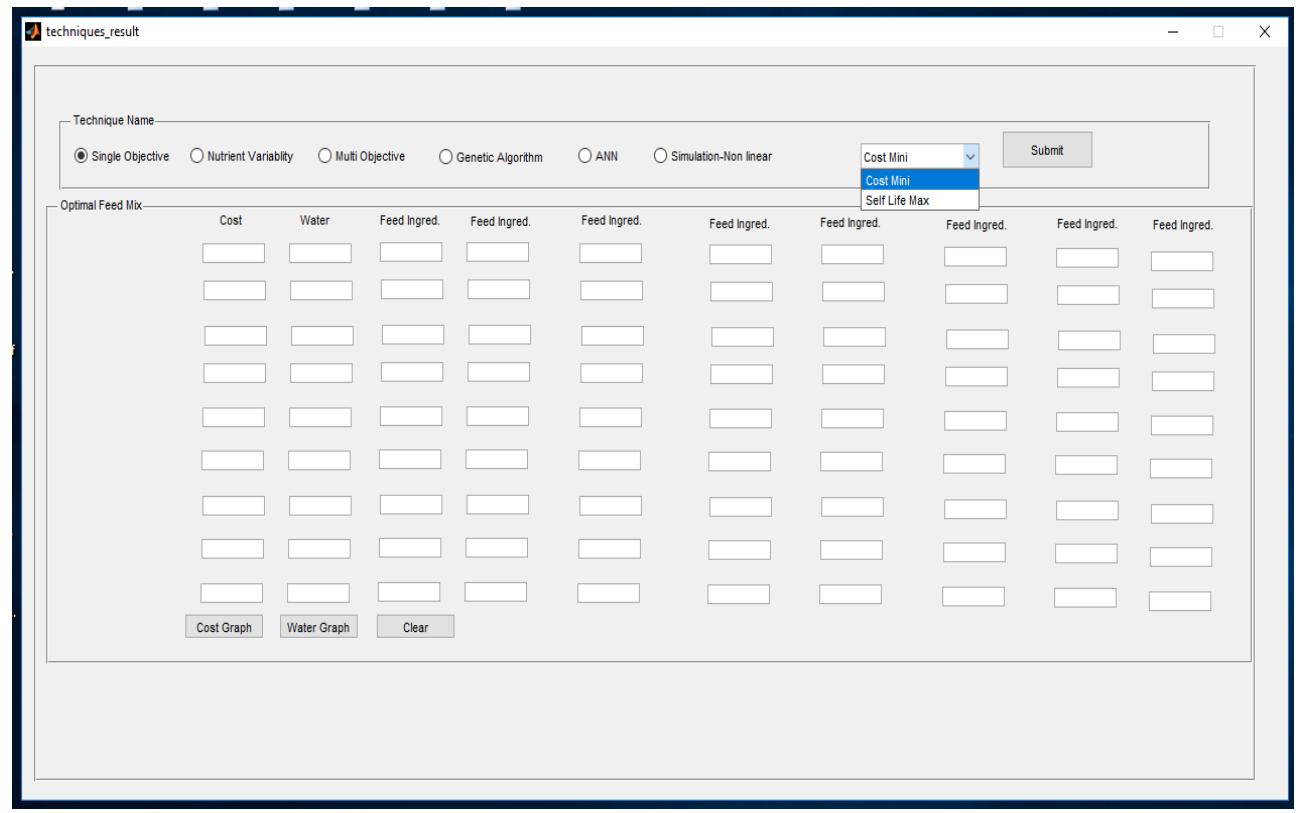

Figure 4. Selection of technique by the user 
International Journal of Mathematical, Engineering and Management Sciences

Vol. 4, No. 2, 337-348, 2019

https://dx.doi.org/10.33889/IJMEMS.2019.4.2-027

Table 1. Different techniques implemented in SIMFEED

\begin{tabular}{|l|l|}
\hline Technique Name & Objective \\
\hline Single Objective & To optimize single objective \\
\hline Nutrient Variability & To include nutrient variability \\
\hline Multiple objective & To consider multiple objectives simultaneously \\
\hline Genetic & To implement genetic algorithm \\
\hline ANN (Artificial Neural Network) & To evaluate simulated feed mix \\
\hline Simulation-Non linear & To compute and evaluate model on the basis of real world data \\
\hline
\end{tabular}

\section{Results and Discussion}

Using SIMFEED, feed mixes can be computed for different livestock. In this section two published problems of least cost feed mix formulation are solved using SIMFEED and the results are verified with the existing results. Firstly, the published problem of dairy cattle (growing holstein heifer) feed mix formulation Saxena and Khanna (2017a) is solved using SIMFEED. In the published paper, results are computed for four different weight classes of the heifers using TORA and LINGO software. The two main objectives in this paper were cost minimization and shelf-life maximization. The results for the same data are obtained using SIMFEED and are validated with the help of feed mixes of the published problem. Using SIMFEED results are extended for simultaneous achievement of multiple objectives. Feed mixes are also computed using genetic algorithm and ANN.

The least cost feed mix for dairy cattle (growing holstein heifer) of $200 \mathrm{~kg}$ weight class using different techniques is shown in Table 2.

Table 2. Results of cost minimization for dairy cattle feed mix

\begin{tabular}{|l|c|c|c|c|}
\hline \multicolumn{1}{c}{$\begin{array}{c}\text { Feed Ingredient } \\
\text { (kg.) }\end{array}$} & \multicolumn{3}{c|}{ Tool Generated Feed Mix } \\
\cline { 2 - 5 } & $\begin{array}{c}\text { Single } \\
\text { Objective }\end{array}$ & With Variability & $\begin{array}{c}\text { Genetic } \\
\text { Algorithm }\end{array}$ & ANN \\
\hline Alfalfa hay & 0 & 0 & 1.450 & 0 \\
\hline Cottonseed hulls & 0 & 0 & 1.956 & 0 \\
\hline Rice bran (fibre 11-20\%) & 0.461 & 2.781 & 1.583 & 1.621 \\
\hline Sugarbeet pulp & 0 & 2.577 & 0 & 1.289 \\
\hline Wheat straw & 5.258 & .462 & 0.816 & 2.860 \\
\hline Cost (Rs.) & 41.410 & 69.708 & 63.353 & 55.559 \\
\hline
\end{tabular}

Table 2 shows that the feed mix, with the single objective of cost minimization and without the inclusion of nutrient variability, has only rice bran and wheat straw as feed ingredients included in the feed mix and the minimum cost of feed mix is Rs. 41.41. This feed mix, achieved using SIMFEED, is the same as in the published paper. The feed mix with nutrient variability inclusion at $80 \%$ probability level has three feed ingredients: rice bran, sugarbeet pulp and wheat straw. The minimum cost is Rs. 69.71. To improve the results in terms of homogeneous feed mix, genetic algorithm feature is included in SIMFEED which is not available in any of the existing tools for livestock feed mix formulation. It is observed that results obtained using genetic algorithm are providing feed mix with four feed ingredients named alfalfa hay, cottonseed hulls, rice bran and 
International Journal of Mathematical, Engineering and Management Sciences

Vol. 4, No. 2, 337-348, 2019

https://dx.doi.org/10.33889/IJMEMS.2019.4.2-027

wheat straw with minimum cost of Rs. 63.35. The inclusion of more number of feed ingredients by this technique validates inclusion of this technique in SIMFEED. Simulated feed mix is obtained by ANN after performing numerous runs. This feature also makes SIMFEED unique as no other existing animal feed formulation software has implemented simulation for fine tuning of feed ingredients. ANN is providing simulated feed mix with three feed ingredients named rice bran, sugarbeet pulp and wheat straw with minimum cost of Rs. 55.56.

Similarly, dairy cattle feed mixes are obtained for shelf-life maximization. Table 3 shows the feed mix of the heifer of $200 \mathrm{~kg}$ weight for shelf-life maximization.

Table 3. Results of shelf-life maximization for dairy cattle feed mix

\begin{tabular}{|l|c|c|c|c|}
\hline \multirow{2}{*}{$\begin{array}{c}\text { Feed Ingredient } \\
\text { (kg.) }\end{array}$} & \multicolumn{4}{c|}{ Tool Generated Feed Mix } \\
\cline { 2 - 5 } & $\begin{array}{c}\text { Single } \\
\text { Objective }\end{array}$ & $\begin{array}{c}\text { With } \\
\text { Variability }\end{array}$ & $\begin{array}{c}\text { Genetic } \\
\text { Algorithm }\end{array}$ & ANN \\
\hline Alfalfa hay & 0 & 0 & 0 & 0 \\
\hline Barley Grain & 0 & 0 & 0.042 & 0 \\
\hline Canola meal & 0 & 3.567 & 0.957 & 1.784 \\
\hline Corn gluten feed & 0 & 0 & 0 & 0 \\
\hline Cottonseed hulls & 0 & 0 & 0.289 & 0 \\
\hline Cottonseed meal & 0 & 0 & 1.8 & 0 \\
\hline Rice bran (fibre 11-20\%) & 0.461 & 0 & 1.741 & 0.230 \\
\hline Sugarbeetpulp & 0 & 0.799 & 0.570 & 0.399 \\
\hline Sunflower meal & 0 & 0 & 0.387 & 0 \\
\hline Wheat straw & 5.258 & 1.431 & 0 & 3.344 \\
\hline Water content (kg.) & 0.519 & 0.574 & 0.597 & 0.547 \\
\hline
\end{tabular}

It is clear from Table 3 that feed mix of dairy cattle for single objective of shelf-life maximization without nutrient variability inclusion also has only rice bran and wheat straw as feed ingredients included in the feed mix and the minimum water content is $0.52 \mathrm{~kg}$. But the feed mix with nutrient variability has three feed ingredients named canola meal, sugarbeet pulp and wheat straw. The minimum water content is $0.57 \mathrm{~kg}$. The feed mixes formulated for shelf-life maximization using SIMFEED are verified with the published results.

The genetic algorithm is providing more homogeneous feed mix with seven feed ingredients named barley grain, canola meal, cottonseed hulls, cottonseed meal, rice bran, sugarbeet pulp and sunflower meal with minimum water content $0.59 \mathrm{~kg}$. ANN is providing the simulated feed mix with four feed ingredients named canola meal, rice bran, sugarbeet pulp and wheat straw with minimum water content $0.55 \mathrm{~kg}$.

The results for cost minimization and shelf-life maximization are also obtained for $300 \mathrm{~kg} ., 450$ $\mathrm{kg}$. and $680 \mathrm{~kg}$. weight class of the heifers using SIMFEED and verified with the existing results. The tabular results for feed mix show that the feed mix by Single Objective-cost minimization is same as the existing results of the published problem. This combination is not able to control the nutrient variability present in the feed ingredients. The feed mix corresponding to nutrient variability inclusion can control the risk of over or under achievement of nutrients at $80 \%$ probability level. More number of programming techniques are included in SIMFEED which is an additional feature and not available in other feed mix formulation software. The genetic 
International Journal of Mathematical, Engineering and Management Sciences

Vol. 4, No. 2, 337-348, 2019

https://dx.doi.org/10.33889/IJMEMS.2019.4.2-027

algorithm provides a homogeneous feed mix with more number of feed ingredients included. ANN provides simulated feed mix after fine tuning of the feed ingredients by observing all the combinations of feed ingredients.

Feed mixes are also formulated to achieve target values of cost, shelf-life and nutrient requirement simultaneously. The multi objective technique is used to achieve these feed mixes for different weight class of dairy cattle. Results of multi objective technique show that goals of cost minimization, shelf life maximization and minimum nutrient requirement can be satisfied simultaneously with little or no deviations from their target values.

Another published linear problem of least cost feed mix formulation is used to validate the working of tool (Nath and Talukdar, 2014). This problem has served as a benchmark in the formulation of feed mix using SIMFEED.

\subsection{Features of SIMFEED}

SIMFEED has a number of features. The list of features is as follows

- SIMFEED is a user friendly interface.

- It is quite simple and easy to understand with some basic knowledge.

- It provides the user an interactive environment to formulate balanced livestock diet.

- SIMFEED provides database for different feed ingredients.

- It also provides standard deviation of nutrients present in feed ingredients.

- Optimal feed mix can be formulated with and without consideration of nutrient variability of feed ingredients at different probability levels.

- Balanced feed mix can be formulated for the simultaneous achievement of multiple objectives.

- Various techniques are used to formulate homogeneous feed mix.

- Feed mix with finely tuned feed ingredients can be achieved using ANN.

- SIMFEED facilitates graphical comparison of values of objective functions achieved using different techniques.

- It works on real data as well as on the data available in the literature.

- SIMFEED also facilitates the formulation and computation of the model on the basis of real world data.

\section{Conclusion}

Since livestock production plays a vital role in the economic growth of any country and livestock production directly depends on nutritionally balanced quality food, fed to the livestock. Only nutritionally balanced quality food can assure better health of the livestock as well as yield and reproductivity. Besides balanced feed mix, various other issues are also involved in the formulation of livestock feed mix such as nutrient variability inclusion, multiple objectives, simulated feed mix etc. SIMFEED is an effort towards developing a simulation tool which can provide different combinations of feed ingredients to fulfill the nutrient requirements of the livestock as well as the different needs of the user. Literature has shown that most of the work done till now is based on the objective of cost minimization. Nutrient variability has been considered by very few researchers. In this paper, the objectives, design and features of SIMFEED are described. SIMFEED is providing an interface which can provide the livestock feed mix to achieve various objectives of the user and livestock industry. The user can achieve the feed mix for the data stored in the data base as well as for the real world data. The working of the tool is validated using 
International Journal of Mathematical, Engineering and Management Sciences

Vol. 4, No. 2, 337-348, 2019

https://dx.doi.org/10.33889/IJMEMS.2019.4.2-027

published problems. Results are also extended using different techniques of the tool to achieve more balanced feed mix. The inclusion of the genetic algorithm is able to provide more homogeneous feed mix. ANN is performing numerous runs and providing simulated feed mix. Simulation methodology makes it possible for the user to formulate and compute the model on the basis of real world data. The inclusion of Genetic Algorithm, ANN and simulation methodology makes SIMFEED unique as no other existing animal feed formulation software has implemented these features on a single platform.

\section{Conflict of Interest}

The authors confirm that there is no conflict of interest to declare for this publication.

\section{Acknowledgement}

The authors would like to express their sincere thanks to the referee and for their valuable suggestions towards the improvement of the paper.

\section{References}

Afrouziyeh, M., Shivazad, M., Chamani, M., Dashti, G., \& Amirdahri, S. (2011). Use of nonlinear programming to determine the economically optimal energy density in laying hens diet during phase 2 . Journal of Applied Poultry Research, 20(1), 50-55.

Black, J. R., \& Hlubik, J. (1980). Basics of computerized linear programs for ration formulation. Journal of Dairy Science, 63(8), 1366-1378.

Jana, M., Panda G., \& Agrawal, N. (2018). An efficient portfolio with several objectives and varying parameters. International Journal of Mathematical, Engineering and Management Sciences, 3(4), 335350 .

Joshi, R. (2016). Artificial neural network based empirical interpolation of precipitation. International Journal of Mathematical, Engineering and Management Sciences, 1(3), 93-106.

Lancaster, L. M. (1992). The history of the application of mathematical programming to menu planning. European Journal of Operational Research, 57(3), 339-347.

Nath, T., \& Talukdar, A. (2014). Linear programming technique in fish feed formulation. International Journal of Engineering Trends and Technology, 17(3), 132-135.

Roush, W. B., Purswell, J., \& Branton, S. L. (2007). An adjustable nutrient margin of safety comparison using linear and stochastic programming in an excel spreadsheet. Journal of Applied Poultry Research, 16(4), 514-520.

Roush, W. B., Purswell, J., \& Branton, S. L. (2009). Microsoft Excel sensitivity analysis for linear and stochastic program feed formulation. Journal of Applied Poultry, 18(1), 1885-1889.

Sahoo, L. (2017). Genetic algorithm based approach for reliability redundancy allocation problems in fuzzy environment. International Journal of Mathematical, Engineering and Management Sciences, 2(4), 259-272.

Saxena, P., \& Khanna, N. (2017a). Modeling for development of simulation tool: Cattle diet formulation. International Journal of Advanced and Applied Sciences, 4(4), 58-66.

Saxena, P., \& Khanna, N. (2017b). Modeling and algorithm development for cattle feed mix formulation. International Journal of Computational Intelligence Research, 13(1). 141-159. 
International Journal of Mathematical, Engineering and Management Sciences

Vol. 4, No. 2, 337-348, 2019

https://dx.doi.org/10.33889/IJMEMS.2019.4.2-027

Shah, N. H., Patel, S. N., Satia, M. H., \& Thakkar F. A. (2018). Optimal control for transmission of water pollutants. International Journal of Mathematical, Engineering and Management Sciences, 3(4), 381391.

Singh, J., Bhati, S., Prasanam, A. R., \& Vayas, A. (2017). Stochastic formulation of fault severity based multi release SRGM using the effect of logistic learning. International Journal of Mathematical, Engineering and Management Sciences, 2(3), 172-184.

Weaver, L. D., Olivas, M. A., \& Galland, J. C. (1988). Identifying features, performance, and limitations of dairy ration formulation software: a comparison of three ration formulation programs. Journal of Dairy Science, 71(4), 1104-1115.

Zgajnar, J. A. K. A., \& Kavčič, S. T. A. N. E (2011). Weighted goal programming and penalty functions: whole-farm planning approach under risk. In EAAE 2011 Congress Change and Uncertainty Challenges for Agriculture, Food and Natural Resources, ETH Zurich, Zurich, Switzerland.

Zgajnar, J., \& Kavcic, S. (2008). Spreadsheet tool for least-cost and nutrition balanced beef ration formulation. Acta Agriculturae Slovenica, 2, 187-194.

Zgajnar, J., Juvancic, L., \& Kavcic, S. (2009). Combination of linear and weighted goal programming with penalty function in optimisation of a daily dairy cow ration. Agricultural Economics-Czech, 55(10), 492-500. 